BULLETIN Bulletin hispanique

HISPANIQUE Université Michel de Montaigne Bordeaux

$115-2$ | 2013

Les traductions vieillissent-elles ?

\title{
El regreso de los muertos
}

Algunos aspectos de la traducción literaria

Costanzo Di Girolamo y Donatella Siviero

\section{(2) OpenEdition}

Journals

Edición electrónica

URL: http://journals.openedition.org/bulletinhispanique/2631

DOI: 10.4000/bulletinhispanique.2631

ISSN: 1775-3821

Editor

Presses universitaires de Bordeaux

Edición impresa

Fecha de publicación: 28 diciembre 2013

Paginación: 439-450

ISBN: 978-2-86781-908-7

ISSN: 0007-4640

Referencia electrónica

Costanzo Di Girolamo y Donatella Siviero, «El regreso de los muertos», Bulletin hispanique [En línea],

115-2 | 2013, Publicado el 14 febrero 2017, consultado el 01 mayo 2019. URL : http://

journals.openedition.org/bulletinhispanique/2631 ; DOI : 10.4000/bulletinhispanique.2631 


\title{
El regreso de los muertos. Algunos aspectos de la traducción literaria
}

\author{
Costanzo Di Girolamo \\ Università di Napoli Federico II \\ Donatella Siviero \\ Università di Messina
}

La traduction artistique a-t-elle une finalité pratique? Dans certains cas elle ne sert à rien, car le public est bien capable de comprendre le texte original. Dans d'autres cas, le seul but du traducteur est de rivaliser avec l'auteur au point que c'est le traducteur qui semble être imité par l'auteur, comme dans le "retour des morts» dont parle Harold Bloom.

Mots-clés : traduction littéraire, traductions inutiles, tradition littéraire, émulation littéraire.

¿La traducción artística tiene una función práctica? Hay casos en que resulta inútil, porque el público es capaz de comprender el original. En otros casos, la unica finalidad del traductor es competir con el autor, e incluso puede llegar a parecer que el autor imita al traductor, como en el "regreso de los muertos» del que habla Harold Bloom.

Palabras claves: traducción literaria, traducciones inútiles, tradición literaria, emulación literaria.

Does artistic translation have a practical aim? In some cases it is of no use at all, since the reader is well able to understand the original text. In other cases, the translator's real aim is to rival the author to such an extent that the translator seems to be imitated by the author, as in Harold Bloom's notion of the "return of the dead".

Keywords: literary translation, useless translations, literary tradition, literary emulation. 
E n 1923, en el ensayo que introducía la versión poética de los Tableaux parisiens de Baudelaire, Walter Benjamin se preguntaba: «¿Una traducción va dirigida a lectores que no comprenden el original?»' . Su respuesta parece ser que sí, pues, como escribe inmediatamente después, de esa finalidad intrínseca deriva «la diferencia de rango en el campo del arte» entre el original y su transposición a otra lengua. En efecto, en la concepción estética del primer Benjamin lo esencial de la obra de arte no estriba en la comunicación; sin embargo, una mala traducción a lo sumo puede pretender comunicar el sentido del original. Una buena traducción, por el contrario, debería «encontrar una tensión hacia la lengua a la cual se traduce que permita despertar en ella el eco del original. [... L La tarea del traductor es rescatar en su propia lengua la lengua pura [es decir la lengua prebabélica, adánica, de la que todas las lenguas conservan algo] encerrada en otra lengua y liberarla en la refundición» $»^{2}$. En todo caso, «así como el tono y el significado de las grandes obras cambia totalmente a lo largo de los siglos, así también cambia la lengua del traductor. Es más, mientras que la palabra del poeta sobrevive en su lengua, hasta la mejor de las traducciones está destinada a formar parte del desarrollo de la lengua y a perecer con su renovación $»^{3}$. Las traducciones literarias, pues, tienen vida breve, una duración que Franco Fortini hasta llegó a medir: a partir de la consideración de que toda traducción, y sobre todo las de poesía, está impregnada de la lengua literaria contemporánea, Fortini afirma que, a causa de las indelebles huellas de su tiempo, «es difícil que una traducción sobreviva más de veinte años, a no ser que se la asuma, junto con la envoltura lingüístico-cultural que la contiene, como un testimonio del pasado", un fenómeno que se da en todas las tradiciones literarias con aquellas traducciones definidas como "clásicas»" ${ }^{4}$.

Parecería, pues, que el traductor está condenado a un trabajo tristemente efímero y que promete muy pocas satisfacciones. Se puede pensar que esto es cierto para las traducciones «de servicio», mientras cabe atribuir otro destino a las traducciones artísticas o a las verdaderas refundiciones, como las que Brecht elogia y practica 5 . En realidad, los ataques de Benjamin y de Fortini van

1. Charles Baudelaire, Tableaux parisiens. Deutsche Übertragung mit einem Vorwort über die Aufgabe des Übersetzers, Heidelberg, Weissbach, 1923, pp. vii-xvii (p. vii). Existen muchas reimpresiones del ensayo (la última en Gesammelte Schriften, 7 tomos en 14 vols., Frankfurt am Main, Suhrkamp, 1991, t. IV-1, 1991, p. 9-21), traducido a las principales lenguas; para comodidad del lector, remitimos a las páginas de la edición original, disponible en la red en el sitio Archive. En el presente trabajo las traducciones de todas las citas son nuestras.

2. Ibid., p. xiii y xvi. El Benjamin premarxista de estos años, en sus ideas sobre el lenguaje, está influido por el pensamiento cabalístico medieval.

3. Ibid., p. x.

4. Franco Fortini, Lezioni sulla traduzione, ed. Maria Vittoria Tirinato, Macerata, Quodlibet, 2011, p. 84. Las conferencias tuvieron lugar en Nápoles en noviembre de 1989, en el Istituto italiano per gli studi filosofici.

5. Véase Franco Fortini, «Traduzione e rifacimento», en Saggi italiani, Bari, De Donato, 1974, p. 332-350. En este ensayo Fortini salva la refundición por ser capaz de actualizar, incluso parodiándolo, un patrimonio literario tradicional; sin embargo, en las Lezioni la refundición se identifica con la traducción de autor allí donde se habla de «alternativa [...] entre traducción 
dirigidos a la segunda categoría, pues ambos, aunque inesperadamente y desde perspectivas divergentes, señalan como modelo la traducción literal e incluso interlineal. «La verdadera traducción es transparente, no cubre el original, no le hace sombra, sino que deja caer enteramente sobre el original, como fortalecida por su medio, la luz de la lengua pura»; por lo tanto, y son las últimas palabras del ensayo de Benjamin, «La versión interlineal del texto sagrado es el arquetipo o el ideal de toda traducción ${ }^{6}$. En cuanto a Fortini, la conclusión de sus Lezioni es que "La traducción privada o de autor es el signo de un apartamiento", de «una aceptación preliminar de la sociedad circunstante y de las instituciones culturales»; por lo tanto, es necesario "perseguir el mínimo de subjectividad y de invención poética a favor del máximo rigor filológico e histórico. Como máximo, se puede ofrecer (con la historia crítica de las versiones del texto que se considera) la posibilidad del do-it-yourself, del «hazlo tú mismo», como en las ediciones interlineales y escolares» ${ }^{7}$.

La austera condena de las "bellas traducciones» por parte de estos dos importantes teóricos, que sin embargo practicaban en primera persona la traducción artística, no se corresponde al prestigio del que la traducción ha gozado en todos los tiempos. Por este motivo, tal vez pueda ser útil tratar de entender cómo los traductores, por lo menos algunos traductores, han interpretado su tarea y cuál ha sido la recepción de dicha tarea. Para ello, volvamos a formularnos la pregunta que se hacía Benjamin, pero tomándola al pie de la letra y suprimiendo sus implicaciones filosóficas: ¡las traducciones están destinadas a quienes no conocen la lengua del original?

Sin duda, contestar que sí es lo más obvio. La primera traducción artística de la tradición europea es la Odisea en versos saturnios, realizada por el liberto Livio Andrónico, cuya lengua materna era con certeza el griego. Así pues, en la Roma del siglo III a. C., la traducción artística nace realmente para un público que ignoraba la lengua del original. La versión de Andrónico, de la que nos han llegado pocos fragmentos, junto con otros textos parciales procedentes de refundiciones que él mismo hizo de tragedias griegas, marca el inicio del fuerte influjo que la cultura griega ejerció sobre Roma y, por lo tanto, es de capital importancia histórica ${ }^{8}$.

Algo semejante parece haber ocurrido en los orígenes de la literatura italiana en la primera mitad del siglo XIII. El fundador de la escuela de poetas de la corte de Federico II, el notario imperial Giacomo da Lentini, traduce en

didáctica y traducción de autor, versión de servicio y versión creativa; y quizás habría que decir, sin demasiado miedo, entre paráfrasis y refundición» (p. 58). En las páginas que siguen, nosotros tampoco distinguimos entre traducción artística (o de autor), que sin embargo comporta una sensible desviación del original, y refundición, término cuyo uso resultaría más apropiado cuando en el tránsito a otra lengua se introducen modificaciones sustanciales, recortes o insertos (algo muy frecuente en las refundiciones medievales).

6. «Die Aufgabe des Übersetzers», p. xv y xvii.

7. Lezioni sulla traduzione, op. cit., p. 184.

8. Los fragmentos se pueden leer, en excelentes ediciones, en el sitio de la Bibliotheca Augustana, www.hs-augsburg.de/-harsch/augustana.html, versión electrónica: Ulrich Harsch, 1997. 
siciliano una canción del trovador Folquet de Marsella, A vos, midontç, voill retrair'en cantan ${ }^{9}$, iniciativa que algunos han interpretado simbólicamente como el inesperado brotar de la lírica italiana del tronco de la tradición trovadoresca. En realidad, los poetas sicilianos sí inauguraron la lírica en Italia, pero es muy probable que tras ellos hubiese una tradición no documentada por escrito, al igual que, sin duda, ocurrió más de un siglo antes con la lírica occitana: es impensable que el primer trovador, el conde Guillermo de Poitiers, crease de la nada una tradición poética. Además, no hay motivos para creer que Madonna, dir vo voglio es el primer poema de la escuela siciliana: contrariamente a lo que se sabía hace varias décadas, hoy en día sabemos con certeza que la poesía de los trovadores era ya conocida y se había difundido no solamente en el norte de Italia, sino también en el sur. Finalmente, añadamos que otros poetas de la escuela de Federico II tradujeron canciones o partes de canciones occitanas ${ }^{10}$. Pero todavía hay más. La poesía de los Sicilianos está tan imbuida de la lengua, las formas y el imaginario de los trovadores, que es imposible que el público no fuese capaz de entender los textos en occitano y que no los conociese desde hacía mucho tiempo. En este caso la traducción pierde su función práctica y va dirigida a «lectores que comprenden el original».

Quedémonos en Sicilia, pero adelantándonos un poco en el tiempo. Dante, y luego Petrarca y Boccaccio imponen gradualmente en Italia el toscano como lengua literaria. Las otras variedades locales no desaparecen, pero adquieren un carácter minoritario. A partir de la primera mitad del siglo XIV y hasta comienzos del XVI, hallamos en Sicilia gran cantidad de textos documentales, prácticos y literarios, casi todos en prosa, escritos en siciliano: textos de archivo, libros de contabilidad, recetarios, tratados hipiátricos; y además crónicas, vidas de santos, confesionarios, tratados religiosos, etc. ${ }^{11}$ Una parte de esta producción, olvidada del gran florecimiento poético de la época de Federico II, está formada por traducciones del toscano o re-traducciones, es decir, traducciones

9. Le poesie di Folchetto di Marsiglia, ed. Paolo Squillacioti, Pisa, Pacini, 1999, p. 414 (también en el sitio Rialto. Repertorio informatizzato dell'antica letteratura trobadorica e occitana, www. rialto.unina.it, ed. Costanzo Di Girolamo, 2001ss., sub Trovatori, n. 155.4; del texto sólo nos han llegado dos estrofas, y de la segunda falta el último verso). La canción de Giacomo Madonna, dir vo voglio se halla en I poeti della Scuola siciliana, vol. I. Giacomo da Lentini, edición crítica con comentario de Roberto Antonelli; vol. II. Poeti della corte di Federico II, edición crítica con comentario dirigida por Costanzo Di Girolamo; vol. III. Poeti siculo-toscani, edición crítica con comentario dirigida por Rosario Coluccia, Milano, Mondadori, 2008, vol. I, p. 5 (también en Rialto, desde la página de la canción de Folquet).

10. Furio Brugnolo, «Traduzioni poetiche nella Scuola siciliana», en Gianfelice Peron (ed), Atti del Premio Città di Monselice per la traduzione letteraria e scientifica, vol. 33. XXXI Convegno: Culture e traduzioni attorno a Federico II, Padova, Il Poligrafo, 2004, p. 270-291.

11. Para una breve síntesis, véase Costanzo Di Girolamo, «La letteratura dialettale siciliana. Dai poeti fridericiani alla fine del secolo XV", en Lingua e dialetto nella tradizione letteraria italiana. Atti del Convegno di Salerno (5-6 novembre 1993), Roma, Salerno editrice, 1996, p. 359-369. El primer texto siciliano fechado es un documento: un decreto de la Curia aragonesa emitido el 16 de agosto de 1320, que impone una gabela para financiar la guerra contra Roberto de Anjou. El corpus de los poetas de la corte de Federico II, originariamente en lengua siciliana, nos ha llegado, a excepción de una canción y pocos fragmentos, en manuscritos toscanizados. 
en siciliano de textos toscanos que a su vez son vulgarizaciones del latín, empezando por la Istoria di Eneas, adaptación siciliana de una vulgarización de 1316 de un compendio latino de la Eneida de la época de Federico III (o II) de Aragón, rey de Sicilia (o de Trinacria) entre 1296 y $1337^{12}$. Todas estas traducciones del toscano al siciliano son literalmente «traducciones inútiles', sobre todo cuanto más nos acercamos al siglo XVI y superamos su inicio, momento en que indiscutiblemente el toscano es reconocido como lengua literaria. Son traducciones inútiles porque, sin lugar a dudas, el público al que estaban destinadas en Sicilia conocía el toscano, como demuestra la presencia en las bibliotecas sicilianas de aquel tiempo de los originales toscanos al lado de las traducciones sicilianas ${ }^{13}$. Por otra parte, se puede descartar cualquier intención artística en esta producción; en general, se trata de textos de escasa calidad, a veces de simples disfraces fonéticos, cuyo grado de literariedad es bajo o inexistente. En este caso, la traducción no tiene una finalidad práctica y no sirve para que unos lectores entiendan una obra escrita en una lengua que ellos ignoran. Aquí, la traducción es un indicio de la vitalidad de una lengua en el ámbito de la escritura y en el territorio de la oralidad, un gesto para atraer la atención de una comunidad que, por ejemplo, podía así volver a leer las famosas historias de Eneas en su idioma materno. El uso del siciliano en textos prácticos (recetarios, tratados hipiátricos) o de contenido religioso (manuales de confesores, materiales útiles para la predicación) resulta todavía más explicable.

El siciliano sobrevive, a partir de comienzos del siglo XVI y hasta hoy en día, no sólo en el habla, sino como variedad escrita para la poesía (a veces poesía de muy alta calidad, desde los petrarquistas del XVI hasta los poetas del siglo $\mathrm{XX}$ ) y en menor medida para el teatro (el mismo Pirandello escribió obras en dialecto); y, como es sabido, poesía y teatro son, esencialmente, las únicas formas de expresión de las literaturas dialectales. Así, las traducciones de los siglos XIV y XV acompañan una tradición literaria que se habría extinguido rápidamente. Existe también el caso contrario, el de las traducciones que sirven para afianzar el prestigio de tradiciones recién nacidas o que renacen.

El ejemplo en el que estamos pensando es, obviamente, el del Don Quijote en catalán. Los primeros intentos de traducción de partes de la obra se produjeron entre 1850 (o quizás antes) y 1879, mientras que la publicación, por entregas, de la primera traducción prácticamente completa, muy literal, de Eduard Tàmaro, empezó en 1882 en El Principado, periódico que al año siguiente dejó de publicarse, con lo cual la segunda parte de la novela quedó inédita. Casi íntegra, aunque con recortes y supresiones, es la traducción, mucho más libre, de Antoni Bulbena i Tusell de 1891. Y todavía más libre es

12. La Istoria di Eneas vulgarizata per Angilu di Capua, ed. Gianfranco Folena, Palermo, Centro di studi filologici e linguistici siciliani, Collezione di testi siciliani dei secoli XIV e XV, 1956: la versión siciliana es probablemente de los años veinte o treinta.

13. Véase Henri Bresc, Livre et société en Sicile (1299-1499), Palermo, Centro di studi filologici e linguistici siciliani, 1971. 
la versión en mallorquín de Ildefons Rullan, aparecida en 1905-1906 y que tenía que dirigirse, como se puede imaginar, a un público muy reducido. La única traducción verdaderamente íntegra es la del lexicógrafo Joaquim Civera i Sormaní, publicada póstuma en $1969^{14}$. Innumerables son las adaptaciones escolares y para niños, sobre todo a partir de la introducción de la enseñanza del catalán en Cataluña, según diferentes modalidades entre 1899 y 1931, luego institucional en los años de la República y al fin obligatoria a partir de 1978.

La utilidad de la operación es muy cuestionable. En casi todas las versiones (menos la última) hubo manipulaciones más o menos considerables de la novela original; por lo tanto, es difícil afirmar que hayan podido servir para hacer la obra de Cervantes más accesible o más comprensible, como reconoce con desarmante honestidad uno de los traductores, que habla del catalán de su época como de «una llengua ja de sí prou insegura»:
consideram quasi del tot impossible donar una solució perfecta en aquells punts intradubibles que l'autor ab meravellosa expontaneitat escrigué, majorment si han d'ésser trasllatats á una llengua ja de si prou insegura ${ }^{15}$.

Es evidente que estas traducciones representan un acto de homenaje no tanto a la obra maestra de la literatura ibérica moderna (que, dicho sea de paso, no lo necesitaba para nada) cuanto a la lengua catalana, cargada de antigua gloria y que, a partir de los años treinta del siglo XIX, volvía a proponerse como lengua literaria y de cultura: se trataba de demostrar que se pueden traducir al catalán hasta las obras más extraordinarias y complejas de la tradición literaria más cercana a la comunidad de hablantes. Tal espíritu de emulación y desafío es muy explícito en las "Cuatre paraulas del traductor» que Tàmaro incluye como prefacio a su traducción, donde incluso utiliza el verbo «competir»:

Es en tal sentit la present traducció una menuda pedreta portada al monument de la gloria de Cervantes; las dificultats que pera portarla á terme se presentan y las que particularment shan ofert al traductor, son facils de coneixer y aquilatar; mes ella, ab tot y sas imperfeccions, podrá tal vegada fer columbrar als més incréduls, la posibilitat de que al costat y sobre las mateixas y hermosissimas planas, en que la llengua castellana, hábilment manejada, rumbeja sas galas més escollidas, la llengua dels Montaners, que es no sols la de las montanyas y homes de guerra, com alguns ab sobrada mala intenció han suposat, sinó

14. Lingeniós hidalgo Don Quixot de la Mancha, traduhit à la lengua catalana per D. Eduart Tàmaro, llicenciat en Jurisprudencia, primera part, Barcelona 1882-1883; L'enginyós cavaller Don Quixòt de la Manxa, traslladat á nostra llengua materna, y en algunes partides lliurement exposat per Antoni Bulbena y Tusell, Barcelona, Tipografía de F. Altés, 1891 (eds. revisadas: Barcelona, Antoni López, 1930 y Sant Feliu de Guíxols, Octavi Viader, 1936); L’enginyós hidalgo Don Quixote de la Mancha, traduit ara en mallorquí sa primera vegada per n'Idelfonso Rullán, prevere, llicenciat en Filosofia i Lletras, 2 vol., Felanitx, Impremta d'en Bartoméu Rèus, 19051906; Don Quixot de la Manxa, traducció de Joaquim Civera i Sormaní, Barcelona, Tarraco, 1969. Sobre toda la cuestión, véase el libro de Montserrat Bacardí e Imma Estany, El Quixot en català, Barcelona, Publicacions de l'Abadia de Montserrat, 2006.

15. Don Quixòt de la Manxa, trad. de Antoni Bulbena, p. vi. 
que fou la dels palaus, del estaments de Corts y de la gaya ciencia, puga competirhi, puix ha escampat ja per tot lo mon l'aroma de sas flors tan delicat com lo més esquisit, y tan independent com ho son las aurenetas ${ }^{16}$.

La inutilidad de los reiterados experimentos con el Don Quijote contrasta abiertamente con la gran utilidad, en el plano de la historia literaria, de la traducción al castellano de comienzos del siglo XVI de una novela catalana del siglo anterior: nos estamos refiriendo, por supuesto, al Tirant lo Blanch de Joanot Martorell, novela que, de un modo totalmente inverosímil, se presenta como traducida por su mismo autor del inglés al portugués y del portugués al valenciano... Presentar una obra como traducción de un original en otra lengua fue un recurso ficcional bastante utilizado en la literatura de la Edad Media, y hasta llegó a convertise en un tópico en los libros de caballerías castellanos del siglo XVI. Normalmente, la falsa traducción presuponía un texto de partida imaginario escrito en lenguas clásicas, importantes: por ejemplo, en el Prólogo del Libro del caballero Zifar, de principios del XIV, se dice que el libro está traducido del caldeo (es decir el arameo de los textos bíblicos) en latín y del latín en romance. Sin embargo, las dos lenguas que cita Martorell debían de ser, en el panorama cultural europeo del siglo XV, relativamente secundarias, de escasa autoridad y ciertamente menos reputadas que otras lenguas como el francés o el italiano. Por lo tanto, la impresión es que Martorell utiliza de manera paródica el difundido tópico de la falsa traducción. Ocuparnos aquí de la compleja historia de la versión del Tirant lo Blanch y de su presencia en el Don Quijote supondría ir más allá de los límites de este trabajo ${ }^{17}$. Sólo recordaremos que la primera edición del Tirant se imprimió en Valencia el año 1490 y debió de tener una difusión limitada al área valenciana. En 1497, salió en Barcelona una segunda edición y catorce años después, en 1511, en Valladolid, se publicó la traducción castellana de la novela, basada en un ejemplar de la impresión barcelonesa. Esta traducción, que había salido completamente anónima, es decir, sin los nombres del autor ni del traductor, muy probablemente fue la versión de la obra que conoció y tanto admiró Cervantes. Posiblemente el escritor nunca llegó a saber que "su» Tirante, la novela que en el famoso escrutinio del capítulo VI del Don Quijote el cura define como «el mejor libro del mundo», no era una obra en castellano del siglo XVI, sino la traducción, además parcial, de una novela catalana medieval. La utilidad de esta traducción, pues, es innegable, ya que permitió a Cervantes conocer una obra que es una de las fuentes del Don Quijote.

16. Don Quixot de la Mancha, trad. de Eduart Tàmaro, p. iii.

17. Para algunas consideraciones sobre el tema se puede ver Donatella Siviero, «Qualche breve riflessione su antenati e eredi di don Quijote», Atti dell'Accademia Peloritana dei Pericolanti. Classe di letteratura, filosofia e belle arti, LXXXIII, 2007, p. 125-137. 
Huelga decir que cuando hablamos de traducciones inútiles no pretendemos insinuar que se trata de operaciones literarias o, más en general, culturales, carentes de significado y motivaciones. Al contrario, la noción de inutilidad, y no la de necesidad o de oportunidad, nos puede ayudar a reflexionar acerca de la importancia y de los distintos significados que se han atribuido a la traducción a lo largo de los siglos. En el ejemplo del Don Quijote en catalán, se ha hablado de dos lenguas que compiten, a pesar de la modestia del traductor de turno. Las cosas se complican cuando la competición se establece entre el traductor y el autor.

Ya hemos hecho referencia al caso de la canción de Folquet traducida por Giacomo da Lentini, un poeta que no se puede considerar, por su calidad poética, inferior al trovador de Marsella. Cuando Giacomo traduce a Folquet entra en una competición "personal» con un poeta famoso y más anciano que él en vez de presentarse como campeón de una nueva e inaudita variedad románica frente a la lengua de la lírica por excelencia. Conviene recordar que las traducciones de vulgar a vulgar (traducciones «horizontales», como las define Gianfranco Folena; «verticales» son en cambio las traducciones del latín al vulgar, es decir las vulgarizaciones) todavía son, a estas alturas de la Edad Media, una operación normal y corriente, equiparable a la refundición en la misma lengua o a la copia que realiza un amanuense de un dialecto a otro, como ocurre sistemáticamente con los textos literarios franceses ${ }^{18}$. Giacomo entra en competición con Folquet no porque puede jactarse de haber transpuesto un texto de un vulgar a otro, sino por haberle devuelto vitalidad a una canción, que debió de ser famosa, dotándola de una forma nueva y, sobre todo, de una nueva métrica, entre otras cosas mucho más compleja que la original. A pesar de la aparente semejanza, se trata de un caso completamente distinto al de Livio Andrónico y al del Quijote catalán.

El ejemplo que acabamos de dar quizá sea poco conocido, al menos para los que no son especialistas en literatura italiana de los orígenes. Otro ejemplo,

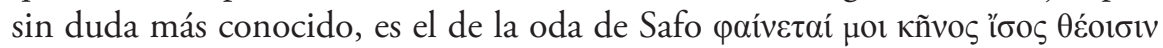
(fr. 31 Voigt): su primer traductor fue Catulo (carmen LI), quien personalizó su versión introduciendo un vocativo a Lesbia (al v. 8) y uno a sí mismo en la última estrofa (al v. 13) ${ }^{19}$. Desde luego, se trata de una traducción más que innecesaria;

18. «En la Edad Media, la variedad de situaciones del traducir es muy amplia, ya sea en relación con los niveles lingüísticos, es decir, tanto si la lengua de partida es el latín como si es una vulgar, ya sea en relación con los niveles culturales y con los géneros literarios [...] Aunque en la perspectiva sincrónica que la Edad Media tiene de las relaciones entre latín y vulgar, [...] hay que distinguir entre un traducir "vertical", en el que la lengua de partida, en general el latín, tiene un valor transcendente con respecto a la lengua de llegada, [...] y un traducir "horizontal" o infralingüístico, que entre lenguas de estructura similar y de gran afinidad cultural adquiere muchas veces el carácter, más que de traducción, de transposición verbal, con un altísimo porcentaje de significantes, lexemas y morfemas comunes e identidad en las estructuras sintácticas, de transmisión y metamorfosis continua, con interferencia máxima y contrastes mínimos.» (Gianfranco Folena, Volgarizzare e tradurre, Torino, Einaudi, 1991, $1994^{2}$ [el ensayo es de 1973], p. 12-13).

19. La traducción es bastante literal en las primeras tres estrofas, mientras que la cuarta y la 
en aquella época, la cultura literaria y la misma escuela romana estaban empapadas de helenismo y la lengua de la poetisa debía de ser comprensible para cualquier persona culta. Es posible que esta oda de Safo sea el poema más traducido (o imitado, reelaborado) de la tradición europea, directamente o a través de la versión de Catulo o de otros. Entre sus traductores (imitadores, reelaboradores) se cuentan Ronsard, Sidney, Boileau, Racine, Joseph Addison, Ignacio de Luzán, Smollett, Ugo Foscolo, Lord Byron, Alfred Tennyson, Gertrudis Gómez de Avellaneda, John Addington Symonds, Vjačeslav Ivanov, Renée Vivien, William Carlos Williams, Carles Riba, Salvatore Quasimodo, Marguerite Yourcenar, Joan Ferraté, Manuel Balasch. El helenista Philippe Brunet ha llegado a recopilar hasta cien versiones solamente en francés ${ }^{20}$.

Si traducir una y otra vez la oda de Safo no responde a ninguna exigencia didáctica, es decir, a la exigencia de dar a conocer o de mejorar el conocimiento del texto, ya que ese texto, al menos desde que se redescubrió en la época humanístico-renacentista ${ }^{21}$, está arraigado en la cultura literaria moderna, es evidente que los reputados intérpretes que se han enfrentado a él han intentado competir, más o menos conscientemente, con quien lo había creado. Pero hay más: la competición acaba por implicar a los otros intérpretes, y el intérprete que llega en último lugar debe hacer un esfuerzo por superar al anterior antes de enfrentarse directamente al autor del original. Naturalmente, nos estamos refiriendo ahora a las traducciones artísticas, a las «traducciones privadas o de autor» de Fortini y no a las que se inspiran en criterios filológicos de cualquier tipo o nivel.

Todo ello recuerda mucho la ansiedad de la influencia que, según Harold Bloom, padece el efebo (es decir, el poeta más tardío, el secuaz, el sucesor) con respecto a su precursor ${ }^{22}$. El secuaz, al final de un complejo recorrido, a lo largo del cual intenta sustraerse a la influencia de su precursor sobre todo mediante malentendidos creativos, acaba completamente embebido de éste último. Ello produce un efecto desorientador («uncanny») en el lector, quien percibe la obra del precursor como si la hubiese escrito el poeta posterior y la obra de este último como si fuera una imitación realizada por el primero ${ }^{23}$. Es

quinta no se corresponden con el original; algunos piensan que se trata de un inserto del poeta latino o de una estrofa espúrea o perteneciente a otro poema. Por otro lado, no sabemos en qué forma leía Catulo el texto de Safo, que a nosotros nos ha llegado truncado.

20. L'égal des dieux. Cent versions d'un poème de Sappho, recueillies par Philippe Brunet, Paris, L'Age d'Homme, 1998.

21. El fragmento está citado en el tratado griego Sobre lo sublime de Pseudo-Longino, editado en 1554 por Francesco Robortello y traducido al francés en 1674 por Boileau. La difusión de la obra de Catulo no es anterior al siglo XIV.

22. Harold Bloom, The Anxiety of Influence: A Theory of Poetry, Oxford - New York, Oxford University Press, 1973.

23. «[...] el efecto extrañante constiste en el hecho de que la realización del nuevo poema no se nos manifieste como la obra del precursor, haciendo de manera que la obra misma del precursor nos aparezca como escrita por el poeta más tardío»; «[...] todos [los grandes poetas] llegan a un estilo que captura y que extrañamente conserva la prioridad sobre sus predecesores, así que la tiranía del tiempo casi se subvierte y se puede pensar, en un momento de desorientación, que 
el último estadio del proceso revisionista: las ả $\pi \circ \varphi \rho a ́ \delta \varepsilon \varsigma$, los días infaustos del calendario ateniense, cuando los muertos regresan a habitar las casas en que habían vivido. El modelo de Bloom parece funcionar perfectamente si lo aplicamos a algunos momentos y aspectos de la traducción artística. Vamos a ver algunos ejemplos italianos.

Sin lugar a dudas, la renovación de la lengua de la poesía y de la prosa italiana durante el siglo XX tiene no pocas deudas con las traducciones, sobre todo con las del inglés. Leyendo las novelas norteamericanas traducidas por autores como Montale, Pavese, Vittorini o Bassani, el público italiano entró en contacto, en particular en el período entre los años treinta y cincuenta, con una sintaxis sencilla y esencial, basada en la parataxis, que ponía en crisis la enrevesada construcción del período, esencialmente hipotáctica, de la narrativa italiana anterior. Algo semejante, aunque de forma más compleja, ocurrió con la poesía extranjera contemporánea, en manos de traductores como Ungaretti, Sereni, Luzi, Fortini o Giudici. Nace, pues, a partir más o menos de los años cuarenta, lo que se ha llamado, a veces con desprecio, otras no, «estilo de traducción», que caracteriza varias novelas y libros de poesía. Aquí, si bien de un modo bastante genérico (y colectivo), comienza a aflorar el modelo de Bloom: algunos autores, en primer lugar los novelistas, utilizan formas y modalidades de escritura que llegan desde lejos, desde otras lenguas, exactamente de las lenguas de las cuales ellos traducen, de manera que el lector tiene la sensación de encontrarse ante traducciones de sus "precursores», es decir, ante traducciones de sus maestros extranjeros.

En determinados momentos, el mismo Fortini parece encarnar el personaje del efebo de Bloom, cuando habla de las «traducciones imaginarias» que se «se leen, con este nombre entre mis versos, y que se titulan también «Imitazione del Tasso» o «Traducendo Brecht» o "Traducendo Milton»; la traducción hipotética se transforma en abierta refundición manierista ${ }^{24}$. Un poeta traductor como Fortini, pues, parece más abierto («open» es el verbo que utiliza Bloom) a las influencias, y no solamente a la influencia de uno sino de un considerable número de precursores, que un poeta común secuaz de alguien; por otra parte, este ejemplo muestra cuán lábiles son los confines entre traducción poética y «traducción hipotética», o, por así decirlo, creación personal.

Otro caso paradigmático es el de Montale traductor de Shakespeare. Antes de 1938, como nos informa en una de sus notas de autocomentario, Montale traduce los sonetos 22, 23 y 48, que aparecieron luego en una revista entre 1944

sean ellos los imitados por sus antepasados» (Ibid., p. 16 y 141).

24. Lezioni sulla traduzione, p. 177. El autor alude a unos poemas, cuyo título es, precisamente, "Traduzione immaginaria», incluidos en sus colecciones poéticas (Una volta per sempre. Poesie 1938-1973, Torino, Einaudi, 1978; Paesaggio con serpente. Poesie 1973-1983, Torino, Einaudi, 1984; Versi primi e distanti. 1937-1957, Milano, All'insegna del pesce d'oro, 1987; Composita solvantur, Torino, Einaudi, 1994; Poesie inedite, Pier Vincenzo Mengaldo ed., Torino, Einaudi, 1995). El hecho de que Fortini incluya entre ellos «Imitazione del Tasso», que, por supuesto, no puede ser una traducción ficticia, es una prueba más de la identificación entre traducción e imitación-refundición. 
y 1947 y que más tarde fueron recogidos en Quaderno di traduzioni (1948). Vamos a leer uno de dichos sonetos, el 48:

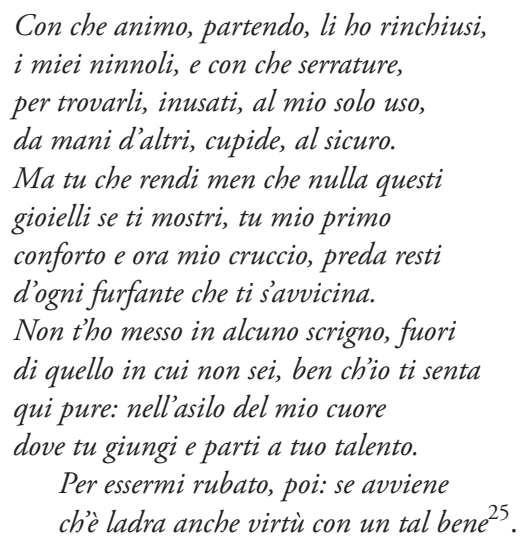

Si lo lee por primera vez alguien que conoce en profundidad a Montale e ignora que se trata de una traducción de Shakespeare, por la lengua y el uso del verso, las rimas y el encabalgamiento, podría pensar que tiene delante un poema típicamente montaliano. También podría darse cuenta inmediatamente de que el metro es el del soneto isabelino, utilizado por Montale en cuatro poemas de la pequeńa colección clandestina Finisterre, publicada en Lugano en 1943, que luego se convertirá en la primera sección de La bufera e altro (1956). Los cuatro sonetos de Finisterre ("Nel sonno», "Gli orecchini», "La frangia dei capelli...", "Il ventaglio») se remontan a los años 1940-1942 y, por lo tanto, son poco posteriores a las versiones shakespearianas. El soneto 48 hasta podría haberle ofrecido a Montale la imagen dominante de «Gli orecchini» (de 1940), es decir, la colocación en primer plano de las joyas:

Non serba ombra di voli il nerofumo
della spera. (E del tuo non è più traccia.)
E passata la spugna che i barlumi
indifesi dal cerchio d'oro scaccia.
Le tue pietre, i coralli, il forte imperio
che ti rapisce vi cercavo; fuggo
l'iddia che non sincarna, i desideri
porto fin che al tuo lampo non si struggono.

25. Eugenio Montale, L'opera in versi, edición crítica de Gianfranco Contini y Rosanna Bettarini, Torino, Einaudi, 1980, p. 713 (la nota de autocomentario está en la p. 1154). [«How careful was I when I took my way, / Each trifle under truest bars to thrust, / That to my use it might unused stay / From hands of falsehood, in sure wards of trust! / But thou, to whom my iewels trifles are, / Most worthy comfort now my greatest grief, / Thou, best of dearest, and mine only care, / Art left the prey af every vulgar thief. / Thee heve I not lock'd up in any chest, / Save where thou art not, though I feel thou art, / Within the gentle dosure of my breast, / From whence at pleasure thou mayst come and part; / And even thence thou wilt be stol'n, I fear, / For truth proves thievish for a prize so dear». William Shakespeare, The Sonnets and A Lover's Complaint, ed. John Kerrigan, Harmondsworth, Penguin Books, 1986, p. 100.] 


\begin{abstract}
Ronzano èlitre fuori, ronza il folle mortorio e sa che due vite non contano. Nella cornice tornano le molli meduse della sera. La tua impronta verrà di giù: dove ai tuoi lobi squallide mani, travolte, fermano i coralli ${ }^{26}$.
\end{abstract}

La imagen de las joyas no carece de precedentes en Montale; pero, tal como señala Avalle, "la imagen se especializa y enlaza definitivamente con el destino del ausente en la Bufera, desde los "Orecchini" [...] hasta "La frangia dei capelli...” («le giade ch'ài / accerchiate sul polso», vv. 5-6)27. Como se puede ver, "Gli orecchini» toma del soneto de Shakespeare, traducido unos ańos antes, tanto la imagen dominante como el tema central de la ausencia. La contigüidad cronológica, el uso de la forma métrica inglesa y algunas imágenes y motivos recurrentes (el espejo en el soneto 22, de nuevo la ausencia en el 23) inducen a considerar conjuntamente los siete sonetos. Por lo tanto, es cierto que "Montale traduciendo cita o refunda a Montale o lo anticipa», como escribe Fortini ${ }^{28}$, pero también es cierto que el lector, a partir del Montale poeta con la inflexión shakespeariana de este período, acaba proyectando sobre el poeta traducido todo cuanto hay de específicamente montaliano y, en definitiva, tiene la impresión de que Shakespeare compuso el soneto con toda la carga montaliana que rezuma la traducción.

En conclusión, podemos observar que la preocupación de Benjamin de que las traducciones tengan solamente la modesta finalidad de transferir un sentido de una lengua a otra se podrá verificar en muchos casos, seguramente en la mayoría de los casos; sin embargo, hemos visto que muchas traducciones, prescindiendo de su calidad, responden a intenciones y tienen implicaciones que no se extinguen ni en la transmisión del sentido ni en la capacidad de «despertar [...] un eco del original». Tanto en el caso de las traducciones inútiles como en caso de que el intérprete entre en competición con su precursor, la traducción no se presenta como una operación de servicio, ni como un auxilio didáctico o filológico, sino que se caracteriza por un grado mayor o menor de manipulación y de instrumentalización del original.

27. D’Arco Silvio Avalle, Tre saggi su Montale, Torino, Einaudi, 1970, p. 46. "La frangia dei capelli...» está en la p. 195 de L'opera in versi.

28. Fortini, Lezioni sulla traduzione, p. 84 en nota. 